Original Article

\section{Mammographic density and its association with molecular subtype of breast cancer. Naila Jabeen $^{1}$ (D), Binish Rasheed ${ }^{1}$ (D), Muhammad Imran² (D), Zoobia Zaheeruddin² (D Anila Rahim ${ }^{1}$ (D)}

${ }^{1}$ Radiology Department, Dow University of Health Sciences, Karachi-Pakistan

2Dow Institute of Medical Technology, Dow University of Health Sciences, Karachi-Pakistan
Doi: 10.29052/IJEHSR.v8.i4.2020.238-248

Corresponding Author Email:

imranduhs19@gmail.com

Received 15/08/2020

Accepted 29/11/2020

First Published 01/12/2020

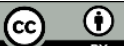

(c) The Author(s). 2020 Open Access This article is distributed under the terms of the Creative Commons Attribution 4.0 International License (http://creativecommons.org/licenses/by/4.0/)

ACCESS

\title{
Abstract
}

Background: Breast cancer is the leading cause of death in women globally. The present study aimed to determine the prevalence of different mammographic density of breast parenchyma along with the association with the molecular subtype of breast cancer.

Methodology: The present cross-sectional study was conducted among breast cancer females age 40 and above. The study participants' demographic and clinical data, such as age, sex, menstrual status, gravida, parity, and lactation, were collected using a standard questionnaire. The anthropometric parameters were taken by using the standard techniques. Breast physical examination, mammography, and ultrasound were done. The ultrasound did the breast tumor biopsy -guided techniques and histopathology, and immunohistochemistry was used to identify the molecular subtype of breast cancer. The univariate and multivariate statistic was performed on SPSS version 20.0.

Results: Most of the patients $<50$ years were human epidermal growth factor receptor (HER2), estrogen receptor (ER), progesterone receptor (PR) positive, and are overweight too. Similar findings were noted among lactating and multigravida patients. The Grade I tumor and dense breast patients were $100 \%$ with HER2 negative and ER, PR positive. Most heterogeneous dense and fibroglandular containing breast patients were ER, PR positive. There is a significant correlation between BMI, microcalcification, and HER2 positive. Most of the triple Negative and Luminal-B were heterogeneous dense.

Conclusion: In conclusion, a significant association between the mammographic density parameters and molecular breast cancer subtype, particularly Luminal-A and luminal B, was seen. The ER, PR, and HER-2 have a positive correlation with the physical radiographical and mammodensity parameters.

\section{Keywords}

Breast Cancer, Breast Cancer Molecular Subtypes, Breast Parenchyma, Breast Mammographic Density.

\section{Check for updates}




\section{Introduction}

Breast cancer is one of the leading causes of death among women, with most of the share belonging to Europe, North America, Australia, and New Zealand ${ }^{1}$. Almost 2.4 million new cases are predicted worldwide, accounting for one in every four cases among western women ${ }^{2}$. Although Asian countries fall behind the western world in the incidence of breast cancer, still Pakistan has a rising trend among Asian countries where one in every nine women experience breast cancer once in life time ${ }^{3}$, and total breast cancer incidence is estimated to be increased by approximately $23.1 \%$ in 2020 to $60.7 \%$ in $2025^{4}$. The worldwide overall mortality rate is reduced due to advancement and timely treatment, but unfortunately in the developing world like Pakistan, we still are striving hard for delayed diagnosis and overburdened health care system.

Dense breast tissue is a significant risk factor for breast carcinoma, and approximately $50 \%$ of females younger than 50 years have a high mammographic density (MD) of the breast. By definition, MD refers to fibro glandular mammary tissue comprising of epithelial cells, fibroblasts, and connective tissue ${ }^{5}$. MD is usually assessed by breast imaging reporting and data system (BIRADS), that divides it into four categories ${ }^{6}$. These categories include fatty parenchyma, scattered fibro glandular parenchyma, heterogeneously dense parenchyma, and too dense parenchyma and are found in approximately 10\%, 40\%, 40\%, and $10 \%$ respectively ${ }^{7}$. Molecular subtypes were assigned by hormone receptor status, tumor grade and include luminal A (ER/PR+ and grade I tumor, ER/PR+, and grade II tumor and ER+/PRand grade I), luminal $B$ (ER+ and tumor having grade III, ER+/PR- and grade tumor and ER/PR+ and tumor having grade II), HER2-positive (ER+ or ER- and HER-2 neu positivity) a triple-negative (ER/PR- and HER-2 neu negative). Few studies have been conducted on the association of mammographic density with molecular breast cancer subtype type ${ }^{8}$. However, most of them were carried out in West or developed in Asian countries. No published data could be retrieved on the current topic in our population. There is a difference in $\mathrm{MD}$ and breast cancer in different ethnic groups ${ }^{9}$. Therefore, there might be a difference in the association between MD and molecular subtype type of breast cancer. Therefore, this study was done to determine the prevalence of different mammographic density of breast parenchyma along with the association of breast mammographic density with the molecular subtype of breast cancer.

\section{Methodology}

This cross-sectional study was conducted at the Dow University of Health Sciences. A total of 250 females age 40 or above diagnosed with breast cancer were considered for this study. Whereas, Women who do not undergo mammography at our institute, who have started treatment of breast cancer without having a mammogram, or women having breast implants or having lumpectomy/breast conservation surgery were not included in this study. The standard questionnaire was designed to take the demographic and clinical data of the study participants such as age, sex, menstrual status, gravida, parity, and lactation. The anthropometric parameters height, weight was recorded by using standard techniques.

The procedure was performed by an experienced radiologist having ten years of women imaging expertise. Physical examination of the breast was done before the ultrasound to evaluate the softness and hardness of the breast and location of the lesion before the procedure. Ultrasound was then performed to look for the imaging characteristics of the lesion followed by an ultrasound-guided trucut biopsy using a 16 gauge needle. Immunohistochemistry for grading and molecular subtypes were followed later. A mammogram was performed on the Senographe digital mammographic machine by General Electronics and two standard Craniocaudal (CC) and Mediolateral oblique (MLO) views of both breasts are taken. Mammographic features that were recorded include breast mammographic density, lesion margin, architectural distortion, skin thickness, nipple retraction, and microcalcification. 
Table 1: The frequency of clinical characteristics and molecular subtypes of the breast

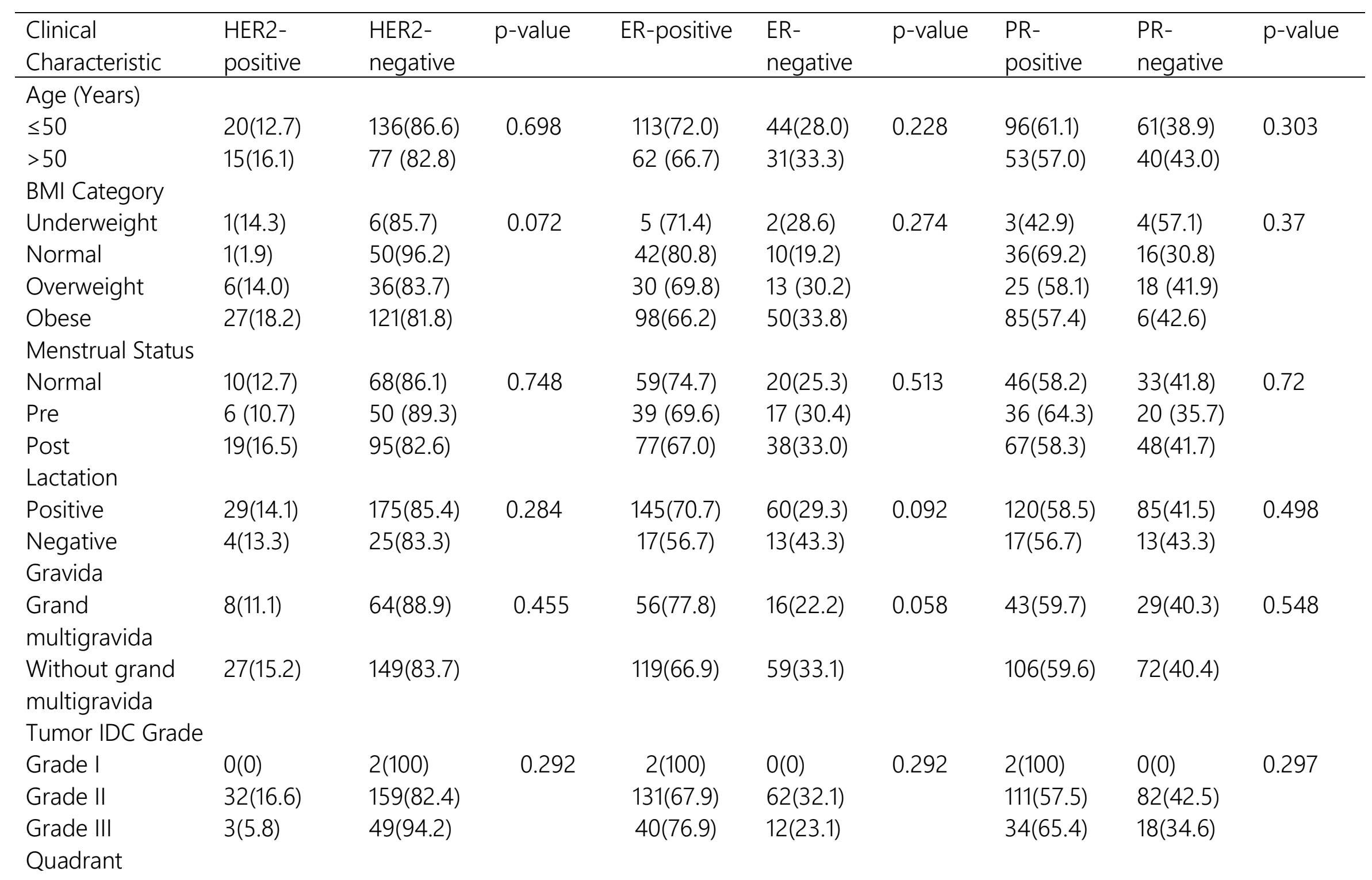




\begin{tabular}{|c|c|c|c|c|c|c|c|c|c|}
\hline Upper Outer & 19(13.6) & $119(85.0)$ & 0.672 & $96(68.6)$ & 44(31.4) & 0.47 & $83(59.3)$ & $57(40.7)$ & 0.983 \\
\hline Upper Inner & $7(10.4)$ & $60(89.6)$ & & $47(70.1)$ & $20(29.9)$ & & $41(61.2)$ & $26(38.8)$ & \\
\hline Lower Outer & $4(20.0)$ & $16(80.0)$ & & $17(85.0)$ & $3(15.0)$ & & $12(60.0)$ & $8(40.0)$ & \\
\hline Lower Inner & $5(21.7)$ & 18(78.3) & & $15(65.2)$ & $8(34.8)$ & & $13(56.5)$ & $10(43.5)$ & \\
\hline \multicolumn{10}{|l|}{ Density } \\
\hline Soft & $26(13.2)$ & $169(85.8)$ & 0.606 & 137(69.5) & $60(30.5)$ & 0.451 & 118(59.9) & $79(40.1)$ & 0.487 \\
\hline High & $9(17.0)$ & $44(83.0)$ & & $38(71.7)$ & $15(28.3)$ & & $31(58.5)$ & $22(41.5)$ & \\
\hline
\end{tabular}

*Values are given as $n(\%)$

Table 2: Mammodensity parameters and molecular subtype of breast cancer

\begin{tabular}{|c|c|c|c|c|c|c|c|c|c|}
\hline $\begin{array}{l}\text { Mamodensity } \\
\text { Parameters }\end{array}$ & $\begin{array}{l}\text { HER2- } \\
\text { positive }\end{array}$ & $\begin{array}{c}\text { HER2- } \\
\text { negative }\end{array}$ & $p$-value & ER-positive & $\begin{array}{c}\text { ER- } \\
\text { negative }\end{array}$ & $\mathrm{p}$-value & PR-positive & $\begin{array}{c}\text { PR- } \\
\text { negative }\end{array}$ & $p$-value \\
\hline \multicolumn{10}{|l|}{ Mamodensity } \\
\hline Fatty & $2(14.3)$ & $12(85.7)$ & 0.996 & $10(71.4)$ & $4(28.6)$ & 0.463 & $8(57.1)$ & $6(42.9)$ & 0.512 \\
\hline Fibroglandular & $16(15.0)$ & $90(84.1)$ & & 70 (65.4) & $37(34.6)$ & & $60(56.1)$ & $47(43.9)$ & \\
\hline $\begin{array}{l}\text { Heterogeneously } \\
\text { dense }\end{array}$ & $17(13.4)$ & 109 (85.8) & & 93 (73.2) & $34(26.8)$ & & 79 (62.2) & 48(37.8) & \\
\hline $\begin{array}{l}\text { Extremely dense } \\
\text { Margins }\end{array}$ & $0(0)$ & $2(100.0)$ & & $2(100)$ & $0(0)$ & & $2(100)$ & $0(0)$ & \\
\hline Well defined & $1(71.1)$ & $13(92.9)$ & 0.897 & $13(92.9)$ & $1(7.1)$ & 0.032 & $12(85.7)$ & $2(14.3)$ & 0.034 \\
\hline III defined & $8(17.0)$ & $39(83.0)$ & & $26(55.3)$ & $21(44.7)$ & & $21(44.7)$ & $26(55.3)$ & \\
\hline Irregular & $24(13.3)$ & $154(85.6)$ & & $130(72.2)$ & $50(27.8)$ & & 110(61.1) & $70(38.9)$ & \\
\hline $\begin{array}{l}\text { Lobulated } \\
\text { US Margins }\end{array}$ & $2(22.2)$ & $7(77.8)$ & & $6(66.7)$ & $3(33.3)$ & & $6(66.7)$ & $3(33.3)$ & \\
\hline Smooth & $4(50.9)$ & $4(50.0)$ & 0.147 & $4(50.9)$ & $4(50.0)$ & 0.367 & $3(37.5)$ & $5(62.5)$ & 0.534 \\
\hline Irregular & $11(10.5)$ & 93(88.6) & & $74(70.5)$ & $31(29.5)$ & & $62(59.0)$ & $43(41.0)$ & \\
\hline lii define & $1(7.7)$ & 12(92.3) & & $8(61.5)$ & $5(38.5)$ & & $7(53.8)$ & $6(46.2)$ & \\
\hline Speculated & $12(16.7)$ & $60(83.3)$ & & $48(66.7)$ & $24(3.3)$ & & $42(58.3)$ & $30(41.7)$ & \\
\hline
\end{tabular}




\begin{tabular}{|c|c|c|c|c|c|c|c|c|c|}
\hline $\begin{array}{l}\text { Lobulated } \\
\text { US Shape }\end{array}$ & $7(13.5)$ & $44(84.6)$ & & 41(78.8) & \multicolumn{4}{|c|}{ US Shape } & \\
\hline Ovoid / Round & 21(15.7) & $112(83.6)$ & 0.713 & $98(73.1)$ & $36(26.9)$ & 0.153 & 78 (58.2) & $56(41.8)$ & 0.362 \\
\hline Irregular & 14(12.1) & 101 (87.1) & & 77 (66.4) & 39(33.6) & & $71(61.2)$ & $45(38.8)$ & \\
\hline \multicolumn{10}{|c|}{ Microcalcification } \\
\hline Cluster & $22(12.6)$ & $150(86.2)$ & 0.849 & $125(71.8)$ & $49(28.2)$ & 0.491 & $105(60.3)$ & $69(39.7)$ & 0.417 \\
\hline Fine & 7 (14.3) & $42(85.7)$ & & $30(61.2)$ & 19(38.8) & & $25(51.0)$ & $24(49.0)$ & \\
\hline \multicolumn{10}{|l|}{ Skin Thickness } \\
\hline Yes & 5 (11.9) & $37(88.1)$ & 0.736 & $26(61.9)$ & 16(38.1) & 0.143 & $19(45.2)$ & $23(54.8)$ & 0.029 \\
\hline No & $30(14.4)$ & $176(84.6)$ & & 149(71.6) & $59(28.4)$ & & $130(62.5)$ & $78(37.5)$ & \\
\hline \multicolumn{10}{|c|}{ Nipple Retraction } \\
\hline Present & $3(13.6)$ & 19(86.4) & 0.905 & $14(63.6)$ & $8(36.4)$ & 0.323 & $13(59.1)$ & $9(40.9)$ & 0.565 \\
\hline Absent & $6(14.0)$ & $37(86.0)$ & & $35(81.4)$ & 8 (18.6) & & $31(72.1)$ & $12(27.9)$ & \\
\hline
\end{tabular}

*Values are given as n(\%) 
Statistical analysis was performed by using SPSS version 20.0. Qualitative variables such as breast density, menstrual status, marital status, the molecular subtype of breast cancer were expressed as frequency and percentage, and quantitative variables such as age as mean and standard deviation. A Chi-square test was applied to evaluate the association of clinical and breast density parameters with the molecular subtype of breast cancer. P-value $\leq 0.05$ was considered as significant. Multivariate logistic regression was used to evaluate the correlation.

\section{Results}

The general characteristics of the patient and immunomolecular markers are illustrated in Table1 and Table 2. Patient characteristics stratified by HER2 gene, ER, and PR status are also presented in Table 1 . The age of the patient $<50$ years showed no difference.

The relationship between immunomolecular markers and clinical characteristics of breast tumor are presented in Table 3 where HER2 score shows a significant probability value with Gravida ( $p=$ $0.056)$ and Microcalcification ( $p=0.047$ ). Significant values were also observed between PR score and Architectural distortion $(p=0.027)$. PR also showed significant results with Skin Thickness $(p=0.038)$, whereas Mammographic density is different with Lactation ( $p=0.053)$ and Menstrual status ( $p=0.007)$. BMl showed significant differences with HER2 ( $p=0.002)$, ER $(p=0.022)$, PR score $(p=0.033)$ and Parity category $(p=$ 0.030). Microcalcification illustrated significant difference with Gravida-category $(p=0.009)$ and HER2 Score ( $p=0.047$ ). Skin thickness showed significant probability difference with Gravidacategory $(p=0.023)$, HER2, $(p=0.008)$, PR $(p=$ $0.0 .038)$ and PR score $(p=0.032)$. However significant difference with nipple retraction with HER2 score $(p=0.039)$ and architectural distortion with ERP score $(p=0.027)$ were also observed. No significant relationship was observed between HER2, ER, and PR score and Margins and Mammogram density in Table 3.

Table 3: Person correlation of clinical characteristics, memodensity and molecular subtype of the breast

\begin{tabular}{lccccccc}
\hline Variables & & HER2 & HER2 Score & ER & ERP Score & PR & PR Score \\
\hline BMI & $\mathrm{r}$ & -0.193 & 0.081 & 0.144 & -0.071 & 0.104 & -0.135 \\
\cline { 2 - 7 } & $\mathrm{p}$ & 0.002 & 0.2 & 0.022 & 0.265 & 0.1 & 0.033 \\
\hline Menstrual Status & $\mathrm{r}$ & -0.054 & 0.054 & 0.072 & 0.002 & 0.004 & -0.048 \\
\cline { 2 - 7 } & $\mathrm{p}$ & 0.394 & 0.395 & 0.255 & 0.976 & 0.946 & 0.451 \\
\hline Lactation & $\mathrm{r}$ & 0.034 & -0.013 & 0.101 & -0.092 & 0.013 & -0.008 \\
\cline { 2 - 7 } & $\mathrm{p}$ & 0.608 & 0.843 & 0.121 & 0.161 & 0.847 & 0.907 \\
\hline Parity & $\mathrm{r}$ & 0.056 & 0.067 & -0.12 & 0.007 & -0.022 & 0.056 \\
\cline { 2 - 7 } & $\mathrm{p}$ & 0.393 & 0.305 & 0.065 & 0.912 & 0.74 & 0.392 \\
\hline Margins & $\mathrm{r}$ & -0.013 & 0.022 & -0.003 & -0.029 & -0.004 & 0.012 \\
\cline { 2 - 7 } & $\mathrm{p}$ & 0.84 & 0.729 & 0.964 & 0.652 & 0.944 & 0.856 \\
\hline Microcalcification & $\mathrm{r}$ & -0.092 & 0.126 & 0.01 & 0.025 & -0.033 & 0.045 \\
\cline { 2 - 7 } & $\mathrm{p}$ & 0.146 & 0.047 & 0.873 & 0.692 & 0.603 & 0.474 \\
\hline Skin Thickness & $\mathrm{r}$ & -0.016 & 0.065 & -0.079 & 0.061 & -0.132 & 0.063 \\
\cline { 2 - 7 } & $\mathrm{p}$ & 0.8 & 0.308 & 0.211 & 0.337 & 0.038 & 0.032 \\
\hline Nipple Retraction & $\mathrm{r}$ & 0.004 & 0.055 & -0.043 & 0.027 & -0.003 & -0.017 \\
\cline { 2 - 7 } & $\mathrm{p}$ & 0.953 & 0.39 & 0.497 & 0.669 & 0.96 & 0.787 \\
\hline Architectural Distortion & $\mathrm{r}$ & -0.01 & -0.049 & -0.113 & 0.14 & -0.116 & 0.108 \\
\cline { 2 - 7 } & $\mathrm{p}$ & 0.881 & 0.442 & 0.074 & 0.027 & 0.067 & 0.089 \\
\hline Parity & $\mathrm{r}$ & -0.02 & -0.149 & 0.087 & 0.019 & -0.002 & -0.045 \\
\hline
\end{tabular}




\begin{tabular}{lccccccc}
\hline \multirow{2}{*}{ Gravida } & $\mathrm{p}$ & 0.752 & 0.019 & 0.169 & 0.76 & 0.97 & 0.477 \\
\hline \multirow{2}{*}{ HER2 } & $\mathrm{r}$ & -0.037 & -0.127 & 0.108 & -0.088 & 0.002 & -0.043 \\
\cline { 2 - 8 } & $\mathrm{p}$ & 0.563 & 0.045 & 0.089 & 0.167 & 0.98 & 0.501 \\
\hline HER2 Score & $\mathrm{r}$ & 1 & -0.425 & -0.389 & 0.362 & -0.399 & 0.363 \\
\cline { 2 - 8 } & & $\mathrm{p}$ & 0 & 0 & 0 & 0 & 0 \\
\hline ER & $\mathrm{r}$ & -0.425 & 1 & 0.02 & -0.168 & 0.16 & -0.009 \\
\cline { 2 - 8 } & $\mathrm{p}$ & 0 & & 0.754 & 0.008 & 0.011 & 0.884 \\
\hline ERP Score & $\mathrm{r}$ & -0.389 & 0.02 & 1 & -0.914 & 0.795 & -0.7 \\
\cline { 2 - 8 } & $\mathrm{p}$ & 0 & 0.754 & & 0 & 0 & 0 \\
\hline PR & $\mathrm{r}$ & 0.362 & -0.168 & -0.914 & 1 & -0.791 & 0.671 \\
\cline { 2 - 8 } & $\mathrm{p}$ & 0 & 0.008 & 0 & & 0 & 0 \\
\hline PR Score & $\mathrm{r}$ & -0.399 & 0.16 & 0.795 & -0.791 & 1 & -0.889 \\
\cline { 2 - 8 } & $\mathrm{p}$ & 0 & 0.011 & 0 & 0 & & 0 \\
\hline Memodensity & $\mathrm{r}$ & 0.362 & -0.009 & -0.7 & 0.671 & -0.889 & 1 \\
\cline { 2 - 8 } & $\mathrm{p}$ & 0 & 0.884 & 0 & 0 & 0 & \\
\hline
\end{tabular}

*BMI-Body Mass Index; HER2-Human Epidermal Growth Factor Receptor 2; ER-Estrogen Receptor; PR-Progesterone Receptor

Table 4: The frequency of breast cancer subtypes and mammographic densities

\begin{tabular}{lcccr}
\hline \multirow{2}{*}{$\begin{array}{l}\text { Sub Types of } \\
\text { Breast Cancer }\end{array}$} & \multicolumn{3}{c}{ Mammographic densities of the breast n(\%) } & p-value \\
\cline { 2 - 4 } & Fatty Breast & Fibro glandular & Heterogeneously Dense & \\
\hline Luminal A & $10(8.7)$ & $35(40.2)$ & $42(48.2)$ & 0.016 \\
\hline Luminal B & $12(17.1)$ & $15(21.4)$ & $53(75.7)$ & 0.036 \\
\hline HER2 neu + & $5(23.8)$ & $9(42.8)$ & $7(33.3)$ & 0.701 \\
\hline Triple negative (TN) & $10(1.6)$ & $12(19.3)$ & $40(64.5)$ & 0.009 \\
\hline
\end{tabular}

\section{Discussion}

In the present study, we examine the association between Breast mammographic density and Immunological markers such as HER2, ER, and PR. It was determined in many recent studies that the percent mammographic density (PMD) (expressed as a percentage of the breast area) associated with many risk factors, notably including BMI, Parity, Gravida, and Menopausal status, that are mainly associated with variations in mammographic density, and also were also associated with differences in one or more of these tissue features ${ }^{10}$. In our study findings, most of the study participants with age $<50$ were ER and PR similar positive trend was seen among overweight patients. According to the finding of the study, similar findings were reported by de Kruijf (2014); the ER-positive were common in the advanced age group and had some significant associations ${ }^{11}$. Eppenberger-Castori's (2002) study also supported our findings ${ }^{12}$.

Furthermore, the Nattenmüller (2018) study was aligned with our study results that BMI was associated with ER/PR positive patients ${ }^{13}$. Although at the same time frame Ma (2018) noted that BMI is inversely associated with ER/PR positive cases ${ }^{14}$. Our findings can be due to the genetic makeup of the study population. In our findings, the ER was positive significantly correlate with $\mathrm{BMl}$; similarly, Phipps (2012) found that the BMI was positively associated with risks of $\mathrm{ER}+$ in advanced age women $^{15}$. The rare of our findings were PR and HER-2 inversely significantly correlated with BMI. The Babu (2018) and Kawai (2014) found similar 
findings; in both research pieces, there were variations in the correlation of $\mathrm{BMI}$ with the subtype of breast cancer ${ }^{16,17}$.

Another unique finding of our study was that the Grade-I tumor patients were 100\% with the presentation of ER/PR positive ${ }^{18}$. Paul (2019) supported our findings that most of the grade-I tumor patients were ER/PR positive ${ }^{19}$. On the other hand, Musa (2018) also accessed the association of HR expression with grading and staging of a tumor; the findings appear that higher-grade tumor (II) was observed (76.93\%) in type IV (ER/PR-, HER2+) and higher stage (III) was observed (80.95\%) in triple-negative subtype ${ }^{20}$. Although, Kaur (2016) found that the Grade-I tumor patients were $0 \%$ ER/PR positive ${ }^{21}$. These findings suggest that the $\mathrm{ER}+/ \mathrm{PR}+$ is a prognostic marker for the noninvasive tumor of the breast. The patients with tumors in upper outer areas also have the highest numbers of patients with ER/PR positive. No study was found to show the relationship between the tumor location and immunological markers to our best knowledge. However, our study does not demonstrate a statistically non-significant difference between all parameters regarding the immunological markers on bivariate analysis.

The breast density, which is considered an essential element by the previous studies, it was also noted that the Percent Mammographic Density (PMD) (expressed as a percentage of the breast area) associated with many risk factors, notably including $\mathrm{BMI}$, parity, and gravida, and menopausal status, that are mainly associated with variations in mammographic density, and in addition, we are also associated with differences in one or more of these tissue features ${ }^{22}$. Thereby, it was shown previously in researches that parity and gravida status were inversely and significantly associated with breast tissue density and collagen percent ${ }^{23}$. In our findings, most of the multigravida study patients were ER-positive, but in the case of the $\mathrm{PR}+/ \mathrm{PR}$ - the study subjects were equal in percentage. Moreover, the HER-2 score had a positive significance correlation gravida. Palmer's (2011) findings were aligned with our findings. These findings supported that at the time of pregnancy and lactation, the breast can be affected by variously specific and unique disorders, including benign disorders closely related to physiologic changes, inflammatory and infectious diseases, etc. ${ }^{24}$. He also found that lactating women are at higher risk of a triple-negative breast cancer type.

Furthermore, in the present study, different breast density parameters were studied to evaluate the best correlation with the immunomarkers. Most of the high-density breast patients' ER+, but the PR+ mostly fell into the soft, dense breast category. The HER2 + were very low in the percentage. Furthermore, it was determined that although the mammographic density is the most crucial risk factor for breast cancer ${ }^{23}$ but according to our results, there are variations associated with the subtypes of breast cancer. One more study have assessed breast cancer's molecular subtypes with different mammographic densities, and contrasting results have been shown ${ }^{15}$. In alignment with our study findings, Tang (2017) also observed similar findings ${ }^{25}$. Thereby, it was determined that though the different subtypes of breast cancer are separate biological entities, lifestyle, however, they are not resulted due to the differences in the mammographic densities and their association.

In our study, the different mammographic density parameters (Table 2) were accessed using the Physical examination, Mammographic and ultrasonic modalities similar to the Tang (2017) study ${ }^{25}$. The findings showed that most of the patients with all density parameters were PR+, although HER2 negative patients were in higher prevalence. A similar study was recently conducted by Li (2019). According to the findings, the results may partially explain the higher proportion of HER2 + tumors ${ }^{26}$, and these findings were not aligned with our study findings.

Among the features, microcalcification and architectural distortion have a significant positive correlation with HER-2 score and PR. Bae found that HER2 status correlated positively with the mammographic calcifications noted 
radiologically ${ }^{18}$. Furthermore, WU (2017) also supported our findings that microcalcification can be conveniently used to facilitate the preoperative prediction of HER2 and Luminal A molecular subtype in patients with infiltrating ductal carcinoma ${ }^{27}$.

Previous studies have also assessed the association of breast cancer's molecular subtypes with different mammographic densities, and contrasting results have been shown. Yang Researches have previously been done to examine the association between mammographic densities and different breast cancer subtypes where receptor status (ER-, PR-, and HER2 status) was used as proxies. The data suggest that increasing dense volume was associated with luminal B and HER2-enriched subtypes among Chinese $^{28}$. Norman $(2017)^{29}$ results suggest mammographic density measures are associated with all 'intrinsic' molecular subtypes. Our study findings found that most of the Luminal-A, Luminal- $B$, and triple-negative subjects were with heterogeneously dense and fibroglandular breast findings. Phipps (2012) conducted a case-control study to assess the association between breast densities, using a BI-RADS classification with different subtypes of breast cancers $^{15}$. They achieved the same results as the current study; that is, the density was similarly associated with all subtypes. However, Edwards (2017) and Razzaghi (2012) found no correlation with the ER/PR positive subtype of breast cancer ${ }^{8,9}$.

Thereby, it was determined that though the different subtypes of breast cancer are separate biological entities, they are not due to the differences in the mammographic densities and their association. Another study by Eriksson (2012) was done to analyze the association between density and the luminal $A$ and basal-like subtypes of breast cancer ${ }^{30}$ and, specifically, does not found any association. We thus believe that our results are not in agreement with both studies. To align with our results Arora (2010), where the association between density and the luminal $A$, luminal $B$, basal-like, and ERBB-2 subtypes of breast cancer was studied, using BI-RADS classification. They observed that women with extremely dense breasts had a higher frequency of luminal-A tumors $^{31}$. Therefore, the results are similar to our study.

Moreover, one more study have also demonstrated that mammographic densities might be partially correlated with breast cancer's molecular pathology and with its subtypes ${ }^{32}$. Shaikh et al. showed similar results that there was a discordant relationship between molecular breast densities and subtypes of breast cancer ${ }^{33}$. According to the latest review, it was demonstrated that most studies had found no association between mammographic densities, hormone receptor status, and molecular subtypes of breast cancer ${ }^{34}$. Moreover, the two recent studies examining the relationship between HER2 status and mammographic density also do not found any association ${ }^{34}$. These studies showed similar results to the current study.

High mammographic density was considered a significant risk factor for breast cancer in females. However, the significantly positive association between mammographic densities and breast cancer subtypes did not vary materially by hormone receptor status, tumor tissue status, or by molecular subtypes defined by hormone marker status. These findings suggested that the association between breast cancer subtypes with mammographic breast densities may be because of other causal pathways. Therefore, future studies are recommended to assess the association with comprehensive information to different parameters like demographic and other risk factors.

\section{Conclusion}

In the current study, it was found that there is a significant association between the mammographic density parameters and molecular breast cancer subtype, particularly Luminal-A and luminal $B$. The ER, PR, and HER2 have a positive correlation with the physical, mammodensity parameters. However; future studies with more sample sizes are recommended to assess the strong prognostic predictor and their association 
with comprehensive information to different parameters like demographic and risk factors.

\section{Conflicts of Interest}

None.

\section{Acknowledgement}

The authors would like to acknowledge the support of the study participants.

\section{Funding}

None.

\section{References}

1. Torre LA, Siegel RL, Ward EM, Jemal A. Global cancer incidence and mortality rates and trendsan update. Cancer Epidemiol Biomarkers Prev. 2016; 25(1):16-27.

2. Bray F, Ferlay J, Soerjomataram I, Siegel RL, Torre LA, Jemal A. Global cancer statistics 2018: GLOBOCAN estimates of incidence and mortality worldwide for 36 cancers in 185 countries. CA Cancer J Clin. 2018;68(6):394-424.

3. Sohail S, Alam SN. Breast cancer in Pakistan awareness and early detection. J Coll Physicians Surg Pak. 2007;17(12):711-712.

4. Zaheer S, Shah N, Maqbool SA, Soomro NM. Estimates of past and future time trends in agespecific breast cancer incidence among women in Karachi, Pakistan: 2004-2025. BMC Pub health. 2019; 19(1):1001.

5. Pettersson A, Graff RE, Ursin G, dos Santos Silva I, McCormack V, Baglietto L, Vachon C, Bakker MF, Giles GG, Chia KS, Czene K. Mammographic density phenotypes and risk of breast cancer: a metaanalysis. J Natl Cancer Inst. 2014; 106(5):dju078.

6. Patterson SK, Roubidoux MA. Update on new technologies in digital mammography. Int J Womens Health. 2014; 6:781-788.

7. Balleyguier C, Ayadi S, Van Nguyen K, Vanel D, Dromain C, Sigal R. BIRADS ${ }^{\mathrm{TM}}$ classification in mammography. Eur J Radiol. 2007; 61(2):192-194.

8. Edwards BL, Atkins KA, Stukenborg GJ, Novicoff WM, Larson KN, Cohn WF, Harvey JA, Schroen AT. The association of mammographic density and molecular breast cancer subtype. Cancer Epidemiol Biomarkers Prev. 2017; 26(10):1487-1492.
9. Razzaghi $H$, Troester MA, Gierach GL, Olshan AF, Yankaskas BC, Millikan RC. Mammographic density and breast cancer risk in White and African American Women. Breast Cancer Res Treat. 2012; 135(2):571-580.

10. Lynge E, Vejborg I, Andersen Z, von Euler-Chelpin M, Napolitano G. Mammographic Density and Screening Sensitivity, Breast Cancer Incidence and Associated Risk Factors in Danish Breast Cancer Screening. Journal Clinical Med. 2019; 8(11):2021.

11. de Kruijf EM, Bastiaannet E, Rubertá F, de Craen AJ, Kuppen PJ, Smit VT, van de Velde CJ, Liefers GJ. Comparison of frequencies and prognostic effect of molecular subtypes between young and elderly breast cancer patients. Molecular Onco. 2014; 8(5):1014-1025.

12. Eppenberger-Castori $S$, Moore $\| D H$, Thor $A D$, Edgerton SM, Kueng W, Eppenberger U, Benz CC. Age-associated biomarker profiles of human breast cancer. Int J Biochemistry Cell Biol. 2002;34(11):13181330.

13. Nattenmüller $C J$, Kriegsmann $M$, Sookthai $D$, Fortner RT, Steffen A, Walter B, Johnson T, Kneisel J, Katzke $V$, Bergmann M, Sinn HP. Obesity as risk factor for subtypes of breast cancer: results from a prospective cohort study. BMC cancer. 2018; 18(1):18.

14. Ma H, Ursin G, Xu X, Lee E, Togawa K, Malone KE, Marchbanks PA, McDonald JA, Simon MS, Folger SG, Lu Y. Body mass index at age 18 years and recent body mass index in relation to risk of breast cancer overall and ER/PR/HER2-defined subtypes in white women and African-American women: a pooled analysis. Breast Can Res. 2018;20(1):5.

15. Phipps Al, Buist DS, Malone KE, Barlow WE, Porter $\mathrm{PL}$, Kerlikowske K, O'Meara ES, Li Cl. Breast density, body mass index, and risk of tumor marker-defined subtypes of breast cancer. Ann Epidemiol. 2012; 22(5):340-348.

16. Babu KG, Anand A, Lakshmaiah KC, Lokanatha D, Jacob LA, Babu MS, Lokesh KN, Rudresha HA, Rajeev LK, Saldanha SC, Giri GV. Correlation of BMI with breast cancer subtype and tumour size. Ecancermedical Sci. 2018;12: 845.

17. Kawai M, Malone KE, Tang MT, Li Cl. Height, body mass index (BMI), BMlchange, and the risk of estrogen receptor-positive, HER2-positive, and triple-negative breast cancer among women. ages 20 to 44 years. Cancer. 2014; 120(10):1548-1556. 
18. Bae MS, Moon WK, Chang JM, Cho N, Park SY, Won JK, Jeon YK, Moon HG, Han W, Park IA. Mammographic features of calcifications in DCIS: correlation with oestrogen receptor and human epidermal growth factor receptor 2 status. European Rad. 2013; 23(8):2072-2078.

19. Paul M, Barman N, Maiti M. Histopatological Spectrum of Breast Carcinomas And Correlation Of Histological Grade With Er, Pr, Her2neu Status In A Tertiary Care Centre Of Eastern India. Int J Scientific Res. 2019;8(10).

20. Musa HN, Hassan AJ. Expression of Estrogen, Progesterone and Human Epidermal Growth Factor Receptors in Breast Cancer in Al-Nassiriya 2014-2015. University of Thi-Qar J Med. 2017;14(2):33-48.

21. Kaur K, Kaur H, Gill HS, Kaur M. Evaluation of expression and correlation of ER PR and Ki67 tumor markers in breast carcinoma. Int J Contemporary Med Res. 2016;3:3047-51.

22. Liu YL, Liu PY, Huang ML, Hsu JT, Han RP, Wu J. Simulation of breast compression in mammography using finite element analysis: A preliminary study. Radiation Phys Chemistry. 2017;140:295-299.

23. Yaghjyan L, Colditz GA, Rosner B, Tamimi RM. Mammographic breast density and breast cancer risk: interactions of percent density, absolute dense, and non-dense areas with breast cancer risk factors. Breast Cancer Res. Treat. 2015;150(1):181-189.

24. Palmer JR, Boggs DA, Wise LA, Ambrosone CB, Adams-Campbell LL, Rosenberg L. Parity and lactation in relation to estrogen receptor negative breast cancer in African American women. Cancer Epidemiology Prevention Bio. 2011; 20(9):1883-1891.

25. Tang C, Ping LI, Zhou X, Luo Z, Huangyi WU. Analysis of the relationship between the characteristics of X-ray and MRI and the level of ER/PR/HER2 expression in breast cancer patients. IJLMR. 2017; 38(24):3404-3407.

26. Li E, Guida JL, Tian Y, Sung $H$, Koka H, Li M, Chan A, Zhang $H$, Tang E, Guo C, Deng J. Associations between mammographic density and tumor characteristics in Chinese women with breast cancer. Breast Cancer Res Treat. 2019; 177(2):527536.
27. Wu M, Ma J. Association between imaging characteristics and different molecular subtypes of breast cancer. Academic Rad. 2017; 24(4):426-434.

28. Yang XR, Tian Y, Guida J, Koka H, Chan A, Guo C, Li E, Tang E, Sung H, Lu N, Hu N. Association between quantitative mammographic density and breast cancer subtypes among Chinese breast cancer patients [abstract]. In: Proceedings of the 2019 San Antonio Breast Cancer Symposium; 2019 Dec 10-14; San Antonio, TX. Philadelphia (PA): AACR; Cancer Res 2020;80(4 Suppl):Abstract nr P5-08-20.

29. Norman AD, Tamimi RM, Scott CG, Bertrand KA, Jensen MR, Visscher DW, Couch FJ, Shepherd J, Fan B, Chen YY, Ma L. Association of mammographic density measures and breast cancer 'intrinsic' molecular subtypes. [abstract]. In: Proceedings of the 107th Annual Meeting of the American Association for Cancer Research; 2016 Apr 16-20; New Orleans, LA. Philadelphia (PA): AACR; Cancer Res 2016;76(14 Suppl):Abstract nr 2593.

30. Eriksson L, Hall P, Czene K, Dos Santos Silva I, McCormack V, Bergh J, Bjohle J, Ploner A. Mammographic density and molecular subtypes of breast cancer. British J Cancer. 2012; 107(1):18-23.

31. Arora N, King TA, Jacks LM, Stempel MM, Patil $S$, Morris $\mathrm{E}$, Morrow M. Impact of breast density on the presenting features of malignancy. Annls Surg oncology. 2010; 17(3):211-218.

32. Ji Y, Shao Z, Liu J, Hao Y, Liu P. The correlation between mammographic densities and molecular pathology in breast cancer. Cancer Biomarkers. 2018; 22(3):523-531.

33. Shaikh AJ, Mullooly M, Sayed $S$, Ndumia R, Abayo I, Orwa J, Wasike R, Moloo Z, Gierach GL. Mammographic breast density and breast cancer molecular subtypes: The Kenyan-African aspect. BioMed Res International. 2018: Article ID 6026315

34. Heusinger K, Jud SM, Häberle L, Hack CC, Adamietz $B R$, Meier-Meitinger M, Lux MP, Wittenberg $T$, Wagner F, Loehberg CR, Uder M. Association of mammographic density with hormone receptors in invasive breast cancers: Results from a case-only study. Int J cancer. 2012; 131(11):2643-2649. 